\title{
O papel do psicólogo na educação profissional e tecnológica: contribuições da Psicologia Escolar
}

\author{
The role of the psychologist in vocational and technological \\ education: Contributions of school psychology
}

\author{
Lígia Rocha Cavalcante FEITOSA' (iD) 0000-0002-0091-932X \\ Claisy Maria Marinho ARAUJO2 (iD) 0000-0001-5411-8627
}

\section{Resumo}

Os Institutos Federais de Educação, Ciência e Tecnologia oferecem cursos que vão do Ensino Médio Técnico à Pós-Graduação, voltados à formação profissional e tecnológica e à formação docente. As transformaçães no ensino profissionalizante, a oportunidade de os estudantes optarem por percursos diferentes na formação e o envolvimento da comunidade acadêmica nos processos educativos tornaram-se objetos de interesse da Psicologia Escolar. Este estudo, de caráter qualitativo, caracteriza a atuação de psicólogos escolares em um Instituto Federal do país. Os resultados revelaram que os participantes possuem uma formação inicial generalista, acompanhada de aperfeiçoamentos nas áreas da Psicologia e da Educação. Em virtude dessa formação, depreende-se que a atuação dos psicólogos escolares, em sua maioria, foi direcionada para ações de apoio aos processos de ensino e aprendizagem dos estudantes. Por outro lado, em alguns relatos foram identificados também os interesses dos psicólogos em propor uma intervenção que se aproxima das contribuições da Psicologia Escolar Crítica.

Palavras-chave: Área de atuação profissional; Educação profissionalizante; Psicologia escolar.

\begin{abstract}
The Brazilian Federal Institutes of Education, Science and Technology offer courses for vocational training from secondary school to post graduation. And they also offer teacher training courses. In this context, the transformations on the vocational training, the students' opportunities to choose different trajectories in their training and the academic community's engagement in the educational process became subjects of the School Psychology. This study -a qualitative one- analyze school psychologists' performance at a specific Federal Institute. The results revealed that the research participants have a generalist background in Psychology and graduate studies in Psychology and Education. It can be
\end{abstract}

$\nabla \nabla v$

${ }^{1}$ Instituto Federal de Educação, Ciência e Tecnologia de Goiás. R. São Bartolomeu, s/n., Vila Esperança, 72811-580, Luziânia, GO, Brasil. Correspondência para/Correspondence to: L.R.C. FEITOSA. E-mail: <ligia.cavalcante.feitosa@gmail.com>.

2 Universidade de Brasília, Instituto de Psicologia, Programa de Pós-Graduação em Processos de Desenvolvimento Humano e Saúde. Brasília, DF, Brasil.

$\boldsymbol{\nabla} \mathbf{v}$

Como citar este artigo/How to cite this article

Feitosa, L. R. C., \& Araujo, C. M. M. O papel do psicólogo na educação profissional e tecnológica: contribuições da Psicologia Escolar. Estudos de Psicologia (Campinas), 35(2), 181-191. http://dx.doi.org/10.1590/1982-02752018000200007 
concluded that, because of such background, the participants performance was generally focused on support to the teaching and learning processes. On the other hand, some reports showed the participants intention to propose actions related, to some extent, to the Critical School Psychology approach.

Keywords: Professional practice location; Educational, professional; School psychology.

No Brasil, entre os anos de 1942 e 1959, o ensino profissionalizante foi concebido para garantir a formação técnica qualificada dentro de um cenário socioeconômico promissor no país. Nesse período, as Escolas Industriais e as Escolas Técnicas Federais foram as primeiras escolas públicas que se responsabilizaram, estritamente, em ofertar cursos voltados para a instrução especializada da força de trabalho e, assim, atender aos interesses do setor industrial e tecnológico brasileiro. Ainda que as mudanças nas políticas educativas tenham alcançado a educação profissional e tecnológica, por muito tempo essa modalidade de ensino fortaleceu a separação entre a formação "intelectual" e "para o trabalho" no contexto educativo.

Apenas a partir da década de 1990, foram adotadas medidas legais que reconfiguraram a Rede Federal de Educação Profissional e Tecnológica. Após mais de uma década dessa reestruturação, em 2008, os Institutos Federais foram criados como alternativa para articular o ensino médio e o ensino técnico, garantir a oferta da educação superior, contribuir para a expansão do ensino por meio da implantação de novas instituições e para formar professores.

De acordo com o Ministério da Educação (2008), os Institutos Federais de Educação, Ciência e Tecnologia (IFET) compareceram como instituições públicas reconhecidas pela oferta periódica de cursos que contemplam do Ensino Médio Técnico à Pós-Graduação, em favor do diálogo entre a formação acadêmica e profissional da comunidade acadêmica. Por meio dos IFET retomou-se a construção dos espaços educativos vinculados à prática da cidadania e da ampla formação do sujeito, a fim de superar as contradições das especializações e fortalecer os processos sociais e de trabalho frutos dessa trajetória.

Considerando esses destaques que envolveram algumas das mudanças na Educação Profissional e Tecnológica no Brasil, é importante evidenciar a nova configuração da comunidade acadêmica nesses espaços. Os reforços institucionais quanto ao quantitativo e às diferentes categorias profissionais, constituídas por equipes multiprofissionais (psicólogos, pedagogos, assistentes sociais, profissionais da saúde); o percurso acadêmico oferecido aos estudantes nos Institutos Federais nos diferentes níveis de ensino e áreas de formação; o perfil heterogêneo de estudantes dos Institutos Federais; a defesa pela articulação entre a formação acadêmica e a formação profissional - todos esses fatores são destaques e desafios presentes no cotidiano para todos os atores educativos dos Institutos Federais, inclusive o psicólogo escolar. Cabe ressaltar que por meio da atuação desse profissional é possível contribuir para o fortalecimento de espaços formativos potencializadores do desenvolvimento humano da comunidade acadêmica.

A atuação do psicólogo escolar será pautada, a partir da mobilização de recursos cognitivos, técnicos, éticos e estéticos, na construção e reconstrução de competências teórico-metodológicas para instrumentalizar as atividades junto aos atores educativos (Marinho-Araujo, 2014). No contexto dos Institutos Federais, a atuação institucional desse profissional poderá mediar, por um lado, as experiências dos estudantes, docentes e gestores frente aos processos de trabalho na trajetória acadêmica e, de outro, as relações sociais, científicas e profissionais que perpassam essa comunidade.

Embora existam produções acadêmicas nacionais sobre as políticas da Educação Profissional e Tecnológica (Cunha, 2005; Frigotto \& Ciavatta, 2003; Kuenzer, 2006; Manfredi, 2002), assim como pesquisas iniciais a respeito das contribuições do psicólogo nesse contexto (Prediger \& Azevedo, 2014), ainda são residuais os estudos que discutem a atuação em Psicologia Escolar junto a essa modalidade de ensino. Neste artigo, o objetivo foi 
caracterizar a atuação dos psicólogos escolares em um Instituto Federal. Para tanto, tornou-se importante apresentar os destaques que constituíram o contexto dos Institutos Federais e evidenciar o cenário de possibilidades para a intervenção da Psicologia Escolar nesses espaços.

\section{Cenário da educação profissional e tecnológica no Brasil}

O interesse pelo crescimento do segmento industrial impulsionou a integração da formação para o trabalho às políticas educativas no Brasil. No ano de 1959, a criação das Escolas Técnicas Federais (ETF) representou uma das iniciativas de reorganização do ensino profissionalizante. Apesar das medidas de promoção da formação profissional no sistema educativo do país, os problemas da evasão escolar, o aumento da procura pelo ensino privado e o crescimento da demanda pelo acesso à Educação Superior contribuíram para que essas escolas não alcançassem a capacitação esperada para o trabalhador. Para contornar esse cenário, em 1970, as ETF foram reestruturadas e tornaram-se Centros Federais de Educação Tecnológica (CEFET).

De acordo com Carvalho (2010), a expectativa com esses novos espaços era de fortalecer o compromisso com o ensino profissionalizante de qualidade, ofertar Educação Superior alternativa às Universidades e constituir força de trabalho para o segmento industrial e de tecnologia, em observância ao momento político e desenvolvimentista no Brasil. Contudo, o que ocorreu foi, mais uma vez, a hierarquização e supervalorização do ensino tecnológico em detrimento do ensino técnico (Campello, 2007).

Mais adiante, no final dos anos 2000, o governo defendeu fortemente a coexistência da formação profissional com o nível superior de ensino como uma meta comum a todos os espaços acadêmicos da Educação Profissional e Tecnológica do país. Nessa direção, os Centros Federais foram transformados em Institutos Federais de Educação, Ciência e Tecnologia (IFET), sendo distribuídos em 38 unidades no país (Ministério da Educação, 2008).
Com os IFET ampliou-se a oferta dos cursos de licenciatura e o número de unidades escolares, bem como o estabelecimento de parcerias estratégicas locais, regionais e nacionais para explorar as potencialidades e oportunidades socioeconômicas nos contextos em que estão implantados. Essa configuração promoveu a aproximação entre academia e sociedade, por meio do fortalecimento de espaços para desenvolver a autonomia reflexiva, teórica e prática da comunidade acadêmica (Andrade \& Kipnis, 2010). Na conjuntura atual, a formação qualificada oferecida nos IFET defende o rompimento da concepção de uma educação meramente voltada para a preparação de mão de obra especializada e de cariz instrucional que, historicamente, vigorou nesses espaços formativos.

O caráter educativo inovador dos Institutos Federais permitiu a defesa da interdisciplinaridade na trajetória formativa dos estudantes e ampliou a necessidade de participação de docentes e gestores no processo de formação intelectual e política da comunidade acadêmica. Diante dessa realidade, acompanhar o debate das políticas institucionais no âmbito do ensino profissionalizante, participar das ações envolvendo o projeto político-pedagógico, apoiar a trajetória dos estudantes, contribuir para a construção do perfil acadêmico e profissional da comunidade acadêmica tornaram-se dimensões de interesse para a Psicologia Escolar. Nessa direção, é importante destacar as construções teóricas acerca da atuação do psicólogo escolar e das suas contribuições para esse contexto.

\section{Construções teóricas da Psicologia Escolar Crítica: implicações para a atuação}

A Psicologia Escolar é compreendida como área de produção de conhecimento, intervenção e pesquisa (Marinho-Araujo, 2010) que, em articulação com a Educação, consolidou-se como um campo de atuação para os psicólogos nos espaços educativos. Entre o final dos anos 1990 e começo dos anos 2000, as produções da área apontaram a importância de se considerarem os diversos aspectos históricos e culturais constituintes dos processos de aprendizagem e de desenvolvimento dos sujeitos 
nos contextos educacionais. Nesse sentido, o psicólogo escolar poderia propor ações junto aos atores educativos, pautadas nos pressupostos da Psicologia Crítica (Martín-Baró, 1996; Parker, 2014) e no compromisso com as demandas sociais e institucionais (Guzzo, 2001, 2003; Marinho-Araujo, 2010, 2014; Petroni \& Souza, 2014).

A Psicologia Escolar Crítica evidenciou a necessidade de se ampliarem os papéis, as responsabilidades e as competências profissionais do psicólogo escolar (Marinho-Araujo, 2010). As reflexões sobre a formação básica e contínua, a ênfase nos estudos acerca do desenvolvimento humano e as propostas de intervenção por meio de ações coletivas com a comunidade escolar representaram as contribuições da área para a concepção e ressignificação da atuação do psicólogo escolar nos diferentes níveis e contextos educacionais (Antunes, 2007; Cruces, 2005; Guzzo, 2003; Marinho-Araujo, 2014; Martínez, 2009; Neves \& Machado, 2007; Petroni \& Souza, 2014).

A descontextualização e a fragmentação do sujeito, a naturalização dos processos de desenvolvimento humano e o caráter individual das práticas psicológicas não poderiam permanecer interligados à atuação do psicólogo escolar. Com o intuito de romper com a intervenção direcionada, quase que exclusivamente, para o atendimento das queixas dos estudantes, defendeu-se a atuação preventiva do psicólogo escolar em atenção aos processos de desenvolvimento humano (Guzzo, 2001, 2003). De acordo com Marinho-Araujo (2005), as práticas críticas e inovadoras em Psicologia Escolar buscam se distanciar das "concepções cristalizadoras acerca do desenvolvimento e aprendizagem, da mudança de foco do fracasso escolar para uma cultura do sucesso, da substituição do paradigma da doença para o da saúde psicológica, na construção de estratégias de intervenção" (p. 97).

A defesa de uma Psicologia Escolar capaz de mediar intencionalmente os processos de aprendizagem e o desenvolvimento dos atores educativos em favor do sucesso acadêmico e das transformações sociais fundamentou a proposta da atuação institucional do psicólogo escolar defendida por Marinho-Araujo (2014). De acordo com tal proposta teórica, esse profissional deve atuar como mediador da construção de diversas estratégias formativas e das possibilidades de aprendizagens dos indivíduos.

Ampliando as concepções apresentadas pela Psicologia Escolar Crítica e a defesa da potencialidade dos contextos educativos, tem-se a realidade da Educação Profissional e Tecnológica como espaço fértil de formação a ser investigado e discutido quanto às possíveis contribuições da atuação do psicólogo escolar. O estudo desenvolvido por Prediger e Azevedo (2014) abordou a construção de um espaço de diálogo virtual para viabilizar as trocas de experiências dos psicólogos atuantes nos Institutos Federais. Por meio de uma pesquisa-intervenção, as autoras construíram um canal de comunicação para discutir e pensar as práticas do psicólogo no âmbito do ensino profissionalizante.

Ainda que se tenha a contribuição desse estudo acerca das experiências do psicólogo na Educação Profissional (Prediger \& Azevedo, 2014), ainda não foram identificadas na produção científica da área as características dos psicólogos escolares dos Institutos Federais, nem a discussão crítica acerca de sua atuação, tampouco os indicadores do perfil profissional e da formação continuada do psicólogo nesses espaços. Nesse sentido, aproximar a historicidade e o papel dos Institutos Federais da revisão das práticas institucionalizadas desenvolvidas pelos psicólogos escolares dos IFET torna-se fundamental para discutir as contribuições da Psicologia Escolar.

\section{Método}

A pesquisa qualitativa é concebida pelo caráter interpretativo dos fenômenos que compõem determinada realidade a ser investigada. Nessa abordagem, é papel do pesquisador orientar o estudo com base em um processo relacional e dialógico junto aos pesquisados, com o intuito de depreender os diferentes significados que eles conferem aos aspectos, aos elementos ou às características de um determinado contexto que os envolve (Denzin \& Lincoln, 2006). 
O estudo foi conduzido em um Instituto Federal localizado na região Centro-Oeste do Brasil, constituído por catorze unidades acadêmicas. A escolha por esse Instituto justifica-se pelo fato de ele representar a instituição pertencente à Rede Federal de Educação Profissional e Tecnológica que mais implantou campi na região nos últimos cinco anos. Além disso, a proximidade geográfica desses Institutos viabilizou o deslocamento da pesquisadora para a condução das entrevistas com os psicólogos escolares. O Instituto Federal pesquisado oferece cursos gratuitos do Ensino Básico à Pós-Graduação, com disponibilidade de vagas anuais a quase vinte mil alunos.

O procedimento inicial para a realização desse estudo foi o de estabelecer contato por e-mail com as Coordenações de Recursos Humanos de cada unidade de um Instituto Federal da região do Centro-Oeste do Brasil, a fim de obter o quantitativo e o e-mail institucional dos psicólogos escolares lotados nos Departamentos das Áreas Acadêmicas ou Coordenações de Assistência Estudantil. Em seguida, ainda com o auxílio do correio eletrônico, foi enviada uma mensagem contendo os objetivos da pesquisa e o convite para que esses profissionais aceitassem participar das entrevistas individuais com a pesquisadora.

Após esse procedimento de contato com catorze psicólogos escolares, onze responderam favoravelmente ao convite e sinalizaram as possíveis datas para o agendamento das entrevistas. Desses participantes, a maioria é do sexo feminino (72\%), com média de idade de 34 anos e de nove anos de atuação como profissional de Psicologia. Todos os psicólogos escolares declararam atuar em setores responsáveis pelo desenvolvimento de atividades vinculadas ao acompanhamento dos processos de ensino e aprendizagem dos discentes e em paceria, majoritariamente, com os profissionais da Pedagogia. O tempo médio de atuação desses profissionais é de três anos e seis meses, depreendendo-se que há um registro recente desses psicólogos no contexto da Educação Profissional e Tecnológica investigado.

Para a entrevista, utilizou-se um roteiro constituído pelos seguintes eixos temáticos: (a) formação do profissional; (b) concepções sobre psicologia escolar e (c) atuação do psicólogo escolar no contexto da Educação Profissional e Tecnológica. A partir desses tópicos orientadores da entrevista, pretendeu-se identificar as frentes de trabalho adotadas pelos profissionais e os diálogos estabelecidos com a formação e concepções a respeito da psicologia escolar.

Para a construção das informações, recorreu-se à técnica de codificação e categorização proposta por Flick (2009). A análise dos relatos dos participantes foi realizada por categorias prévias, contempladas na estrutura do roteiro das entrevistas, que favoreceram o agrupamento das falas dos psicólogos escolares relevantes e coadunados aos objetivos da pesquisa. A partir dessa categorização, a interpretação dos resultados foi subsidiada pelo referencial teórico da área e o contexto de investigação.

\section{O Psicólogo escolar no Instituto Federal: aspectos da formação}

A primeira categorização que emergiu da análise das informações foi definida por "formação do profissional". Essa categoria refere-se aos aspectos caracterizadores da formação inicial e continuada do psicólogo escolar atuante nos campi investigados. A partir dos relatos dos respondentes, pode-se compreender as trajetórias formativas e analisar as ênfases desse profissional no contexto de um Instituto Federal.

A formação do psicólogo escolar foi objeto de análise de diversos estudos no cenário internacional e nacional. A respeito da trajetória de formação dos psicólogos em contexto educativo, os estudos conduzidos em diferentes países apontaram a prevalência das ênfases nas áreas clínica e da saúde nos cursos de Psicologia (Jimerson, Alghorani, Darweish, \& Abdelaziz, 2010; Mendes, Abreu-Lima, Almeida, \& Simeonsson, 2014). No tocante às lacunas no currículo da formação de base específica e na ausência de uma proposta de intervenção crítica envolvendo as áreas da Psicologia e da Educação, estudos apontaram a necessidade de se revisitarem as Diretrizes Curriculares Nacionais 
dos cursos de Psicologia, a fim de contemplar as especificidades requeridas para atuação desse profissional no contexto educativo (Cruces, 2005; Guzzo, 2001; Marinho-Araujo, 2005).

Embora neste estudo o Instituto Federal tenha se revelado como um espaço promissor para a Psicologia Escolar, os relatos dos participantes evidenciaram que em sua formação o enfoque na psicologia clínica e organizacional foi o mais difundido quando comparado à área da psicologia escolar. Denominados pelo edital do concurso como psicólogos institucionais, os participantes relataram também a dificuldade em atuar sob a perspectiva da Psicologia Escolar. Depreende-se que, em virtude da formação generalista desses profissionais e da falta de clareza do edital a respeito de suas atribuições, as competências necessárias para intervir em seus contextos educativos não foram desenvolvidas com facilidade pelos psicólogos escolares.

A formação inicial referente à Psicologia Escolar foi considerada como deficitária pelos participantes. O relato de P1 revela que "durante a minha graduação cursei, apenas, uma disciplina de Psicologia Escolar que discutia basicamente as práticas iniciais de diagnóstico no contexto da escola". A fala de P2 reforçou a fragilidade da formação ao apontar "eu não tive nenhuma disciplina de Psicologia Escolar no decorrer da minha graduação, a temática que mais se aproximou foi de uma disciplina de necessidades educativas". Para P3 a oportunidade profissional foi que viabilizou o contato com a área, "Ingressar na instituição via concurso público foi minha primeira oportunidade de trabalho com a psicologia escolar, antes eu atuava na área da assistência social e meu contato com a escolar tinha sido pontual em estágios ou observações na escola". Em consonância com esses exemplos, os demais oito psicólogos afirmaram que o contato com a Psicologia Escolar foi proveniente de estágios na Licenciatura; de demandas recebidas na Clínica; de parcerias com a intervenção da Psicologia Comunitária e de práticas docentes na Educação Superior. Por meio desses relatos, pode-se identificar que essas experiências retrataram uma formação distante das reais contribuições da Psicologia Escolar para uma intervenção crítica nesses espaços.
Apesar de os relatos dos participantes anunciarem as lacunas na formação em Psicologia Escolar, pode-se identificar um movimento de busca pela continuidade do aperfeiçoamento profissional em decorrência das demandas educativas e particularidades de uma intervenção multidisciplinar no contexto do IFET. Dos 11 profissionais entrevistados, seis possuem Mestrado na área da Psicologia do Desenvolvimento e Educação; dois possuem Mestrado na área da Psicologia com ênfase na área das Organizações, na área de Ciências Humanas com o enfoque nas Medidas Socioeducativas; e três possuem Especialização em Psicopedagogia e na Educação Pré-Escolar. No que diz respeito às formações complementares, foi relatado o interesse pelo aperfeiçoamento envolvendo a atuação do psicólogo no Instituto Federal, nas dificuldades de aprendizagens, na prevenção do uso de drogas, na orientação vocacional e profissional, no psicodiagnóstico, na educação especial e na psicopedagogia. O aprimoramento ocorreu, majoritariamente, a partir do ingresso desses profissionais em seus campi de lotação.

Pode-se depreender que o interesse pela melhoria da formação desses psicólogos escolares associou-se à necessidade de qualificar as propostas de intervenção nos espaços institucionais e de fundamentar uma prática que demarcasse a identidade do psicólogo escolar. De acordo com Guzzo (2001), a mobilização por estratégias de aperfeiçoamento pode representar a iniciativa desses profissionais em garantir uma melhor compreensão das especificidades de sua atuação. O investimento em ações contínuas de aprimoramento profissional pode contribuir para fortalecer a base teórico-metodológica do psicólogo escolar, de modo a desenvolver intencionalmente ações práticas consistentes que envolvam a todos os atores educativos. Nesse sentido, a formação continuada pode permitir ao psicólogo escolar o avanço nas propostas de uma intervenção comprometida e que, em certa medida, envolva a todos os atores educativos.

A partir dos relatos sobre a formação, pode-se compreender que o reconhecimento das lacunas 
no currículo de base e a percepção das demandas no contexto educativo foram os argumentos utilizados por esses psicólogos escolares para definir as escolhas por cursos ou atualizações com interface entre a Psicologia e a Educação. Por outro lado, ficou evidente também que esses percursos de aperfeiçoamento ainda estão fundamentados em concepções teóricas que direcionam a intervenção para possíveis queixas escolares e aspectos psicossociais dos estudantes no cotidiano escolar. Embora se reconheça que essas questões integram a realidade acadêmica do Instituto Federal, elas não são as únicas responsáveis pelos processos de desenvolvimento humano dos atores educativos. Promover o processo de ensino e aprendizagem; reconhecer as especificidades da trajetória acadêmica dos estudantes nos mais diferentes níveis de ensino e construir ações intencionais e mobilizadoras de toda a comunidade acadêmica para uma formação humana e crítica são exemplos para retroalimentar os motivos desses profissionais na busca pela formação continuada em Psicologia Escolar (Marinho-Araujo, 2014).

\section{Concepções sobre a Psicologia Escolar na formação e para atuação}

A categoria "concepções sobre a Psicologia Escolar" revelou o entendimento construído e compartilhado pelos participantes a respeito da área. As produções acadêmicas referentes à Psicologia Escolar revelaram a falta de clareza de psicólogos acerca dos pressupostos epistemológicos das teorias psicológicas como uma das barreiras para o desenvolvimento de intervenções, procedimentos e instrumentos que de fato promovessem as potencialidades de sua atuação (Guzzo \& Mezzalira, 2011; Marinho-Araujo, 2014; Martinez, 2009). Entendendo a formação como uma dimensão necessária para constituir as concepções sobre a Psicologia Escolar, os relatos dos participantes evidenciaram as percepções que construíram ao longo da sua atuação.

Quando consultados acerca do que compreendiam a respeito da Psicologia Escolar, esses profissionais demonstraram ter concepções gerais sobre a área. Em alguns momentos apresentaram reflexões e pausas para a construção de suas respostas e, mesmo não conseguindo esclarecer o "que fazem" e "como fazem", sinalizaram desconforto com a reprodução de uma atuação de perspectiva individualizante e foco exclusivo em atendimentos aos estudantes.

Nesse sentido, a fala de P4 concebe a Psicologia Escolar como uma área para "Trabalhar com desenvolvimento humano dentro do contexto educativo. Implementar melhorias no processo do ensino e aprendizagem é um processo não do individuo, mas institucional. Envolve alunos, docentes, servidores administrativos, o espaço físico, a cultura da instituição". Ainda no relato de P5, essa área é entendida como "... a que dialoga com a Psicologia e Educação que por muito tempo, e acho que até hoje, possui um viés diagnóstico e individual, enxergando o aluno como situação problema ...". Para P6, essa definição perpassa por "identificar o papel do psicólogo nos processos de mediação das relações e desconstruir o modelo clínico na escola".

Os relatos descritos apontaram reflexões inovadoras envolvendo a intervenção do psicólogo escolar no âmbito de uma atuação crítica e institucional. Nas falas desses psicólogos escolares são apontados os incômodos com os pressupostos individualizantes e deterministas dos processos de desenvolvimento humano, bem como uma preocupação com a psicologização das queixas escolares. Em resposta a esses tensionamentos, os psicólogos escolares sinalizaram o interesse na proposição de atividades com os demais atores educativos, considerando as vozes institucionais construídas e partilhadas pela comunidade acadêmica. Os processos de ressignificação da formação e da concepção sobre a área constituem o cerne das intervenções críticas e inovadoras dos psicólogos escolares.

Nesse estudo, os relatos dos psicólogos escolares apontaram para um movimento ainda embrionário de ressignificação da sua identidade profissional em seus campi. Embora as concepções que possuem sobre a Psicologia Escolar estejam mais permeadas pelas expectativas de revisão da 
sua atuação, compreende-se que essa transição pode ser favorável para a sistematização de uma proposta de implementação efetiva da intervenção crítica e institucional de psicólogos escolares em um Instituto Federal.

\section{Relatos de experiências dos psicólogos escolares em um Instituto Federal}

A categoria "atuação profissional" permitiu evidenciar alguns relatos de práticas desses profissionais, bem como identificar as bases para a proposição de tais ações, as parcerias estabelecidas no contexto educativo e as potencialidades e desafios presentes em seu cotidiano de atuação. Apresentar o que faz o psicólogo escolar em um Instituto Federal permitiu identificar as ênfases de sua intervenção no contexto da Educação Profissional e Tecnológica.

Historicamente, o processo formativo instituído nas escolas profissionalizantes foi marcado por um ensino tecnicista. As mudanças nas políticas educacionais ampliaram o conjunto de responsabilidades atribuídas aos Institutos Federais. Dentre elas, destaca-se a coexistência de diferentes níveis de ensino e a análise dos indicadores da empregabilidade para a capacitação profissional que fortaleceram a educação básica, a técnica e a formação em nível superior da comunidade acadêmica. Esse novo contexto proporcionou ao psicólogo escolar possibilidades de uma atuação promotora do desenvolvimento dos atores educativos de forma competente, crítica e consciente. A atuação desses profissionais no Instituto Federal fundamentou-se em dois grandes eixos: acompanhamento da comunidade discente e participação nas políticas de assistência estudantil.

Acolher as demandas educativas dos estudantes, disponibilizar espaços para escuta psicológica, participar das reuniões acadêmicas e envolver os responsáveis pelos estudantes no cotidiano da escola são as ações que compõem a intervenção desse profissional junto ao suporte dos alunos. Na fala de P7 tem-se o exemplo da atuação com o "foco no aluno, trabalhamos com a formação de grupos, disponibilizamos espaço para escuta psicológica; reservamos espaço para atendimento de pais e participação nas reuniões acadêmicas". De forma complementar ao disposto, P8 diz que "por meio de trabalho com projetos que se pode [sic] abrir espaços da escuta das demandas que chegam ainda em formato de diagnósticos". Esses relatos apontaram a coexistência de uma intervenção centralizada nas questões referentes à trajetória acadêmica e no apoio psicológico dos discentes.

O estudo conduzido por Jimerson et al. (2010) apontou que as atividades dos psicólogos estão voltadas principalmente para o aconselhamento aos estudantes, os projetos de prevenção primária e a avaliação psicoeducacional. Diferentemente da maioria dos resultados de estudos europeus, Mendes et al. (2014) identificaram que esses profissionais estavam dedicados à prática de avaliação e aconselhamento, mas com investimento maior em orientação profissional, educação especial e promoção do bem-estar.

Na perspectiva da Psicologia Escolar Crítica, Andrada (2005) apontou que a ênfase clínica da atuação do psicólogo escolar precisa ser revisitada, pois o atendimento individualizado das questões psicológicas não é capaz de lidar com as complexidades da realidade escolar. Nesse sentido, Marinho-Araujo (2014) propõe que o trabalho do psicólogo escolar esteja voltado para as atuações coletivas e para as inúmeras tentativas de superar as concepções conservadoras de adaptação e psicologização presentes nas práticas psicológicas tradicionais dos contextos educativos.

Em relação às ações referentes à assistência estudantil, tem-se o trabalho de apoio do psicólogo escolar na concessão de benefícios sociais à comunidade acadêmica e nas parcerias estabelecidas com outros profissionais do Instituto Federal, a fim de promover espaços de inclusão, desenvolvimento e reflexão dos discentes no percurso escolar. Para P11, "... já existe uma participação nossa no acompanhamento das políticas educacionais, ... quando se têm os editais de auxílio permanência, transporte e alimentação no campus, geralmente atuo identificando os indicadores psicossociais do estudante, a trajetória escolar e seu envolvimento 
com a escola ...". De acordo com P10, o trabalho precisa ser "alinhado com as propostas de trabalho da equipe multidisciplinar, num enfoque ampliado ... É preciso promover a permanência e a inclusão dos nossos alunos nas atividades acadêmicas". Trabalhar em conjunto com outros atores educativos (assistentes sociais, pedagogos e professores) no contexto da assistência ao discente foi visto como um aspecto inovador para os psicólogos escolares do Instituto Federal que, tradicionalmente, foi reforçada por uma atuação solitária e clínica. A fala de P9 retomou a preocupação desse profissional em pensar em uma intervenção estendida a todos àqueles que constituem o contexto educativo, alertando que é preciso superar o paradigma do "aluno ser o problema e o foco da nossa intervenção".

Diante dos relatos apresentados, podem-se evidenciar os aspectos contraditórios entre as concepções e as atuações dos profissionais da área no contexto da Educação Profissional e Tecnológica. Por um lado, têm-se psicólogos escolares sensíveis à ressignificação do que foi concebido tradicionalmente por Psicologia Escolar; e de outro, têm-se os mesmos profissionais questionando a continuidade de ações práticas que ainda reverberam os indicadores de uma atuação de caráter psicoterapêutico e individualizante. A manutenção dessa lacuna pode conduzir o psicólogo escolar a ações que naturalizem as queixas e responsabilizem exclusivamente o discente frente às dificuldades adaptativas e aos possíveis insucessos acadêmicos

Ainda que se tenham elementos dissonantes entre a formação, as concepções e as experiências de psicólogos escolares em um Instituto Federal, os relatos apresentados exemplificaram que o aperfeiçoamento profissional e o contato com as especificidades do contexto educativo podem conduzi-los às reflexões iniciais para a construção de uma atuação coletiva e institucional. Repensar as ênfases das atividades desenvolvidas por esses profissionais; investir na formação continuada; mapear as demandas acadêmicas e institucionais; e propor ações conscientes articuladas à realidade dos atores educativos e ao funcionamento da instituição, são aspectos que poderão compor a trajetória de consolidação da Psicologia Escolar no contexto da Educação Profissional e Tecnológica.

\section{Considerações Finais}

No Brasil, as mudanças no contexto da Educação Profissional e Tecnológica proporcionaram elementos relevantes para compreender a redefinição dos objetivos do ensino profissionalizante e a importância de se privilegiar um currículo integrado e ofertado em diferentes níveis de ensino, bem como para promover o crescimento da comunidade acadêmica nos Institutos Federais. Diante desse cenário, a atuação dos psicólogos escolares tem sido requerida para propor diferentes ações práticas que contribuam para o apoio especializado às demandas da comunidade acadêmica nesses espaços educativos. Evidenciar os aspectos da formação, das concepções e da atuação desses profissionais em um Instituto Federal permitiu discutir introdutoriamente as construções da intervenção psicológica nesses espaços e, ainda, apontar as potencialidades para uma atuação sob a perspectiva da Psicologia Escolar Crítica.

Nos relatos dos psicólogos escolares foi identificada a predominância dos aspectos generalistas em sua formação inicial, com embrionárias interlocuções com a Psicologia Escolar. A busca pela formação continuada desses profissionais esteve motivada, quase que majoritariamente, pelo contato com as demandas escolares constituídas em seus espaços de atuação no Instituto Federal. A partir desse interesse, os psicólogos puderam incrementar sua atuação, com intervenções voltadas ao acompanhamento da comunidade discente e à participação nas políticas de assistência estudantil. Mesmo que esses profissionais tenham demonstrado preocupação com a prática clínica e individualizante de sua atuação, muitos ainda apresentam dificuldades em propor ações práticas fundamentadas nos processos de desenvolvimento humano para toda a comunidade acadêmica, bem como em ressignificar a escuta psicológica ou implementar propostas de trabalho que ampliem o espectro da sua intervenção no contexto do ensino profissionalizante. 
Espera-se que, a partir da caracterização da intervenção de psicólogos escolares em um Instituto Federal, sejam propostos outros estudos na temática que discutam o perfil profissional e aprofundem os indicadores para sua atuação nos Institutos Federais. A oferta de diferentes níveis de ensino e as políticas institucionais em favor da articulação entre formação acadêmica e atividade profissional, bem como as motivações e as expectativas dos estudantes apresentam-se como dimensões que podem ampliar as contribuições da Psicologia Escolar nos Institutos Federais. Além disso, evidenciar o papel desse profissional nos IFET torna-se necessário para consolidar uma atuação baseada em concepções sobre a Psicologia Escolar que esteja alinhada à intervenção de caráter preventivo e institucional e que, por conseguinte, contribua para a formação na Educação Profissional e Tecnológica e para a defesa de um currículo acadêmico integrado à práxis.

\section{Colaboradores}

L.R.C. FEITOSA e C.M. MARINHO-ARAUJO participaram conjuntamente das etapas referentes à concepção e desenho da pesquisa, revisão bibliográfica, construção dos resultados, discussão das informações, revisão parcial e final do artigo.

\section{Referências}

Andrada, E. G. C. (2005). Novos paradigmas na prática do psicólogo escolar. Psicologia: Reflexão e Crítica, 18(2), 196-199. http://dx.doi.org/10.1590/S010279722005000200007

Andrade, A. F. B., \& Kipnis, B. (2010). Cursos superiores de tecnologia: um estudo sobre as razões de sua escolha por partes dos estudantes. In J. Moll (Ed.), Educação profissional e tecnológica no Brasil contemporâneo (pp. 175-191). Porto Alegre: Artmed.

Antunes, M. A. M. (2007). Psicologia escolar e educacional: história, compromisso e perspectivas. Cadernos de Psicopedagogia, 6(11), 469-475. http://dx.doi. org/10.1590/S1413-85572008000200020

Campello, A. M. M. B. A. (2007). "Cefetização" das escolas técnicas federais: projetos em disputa nos anos 1970 e nos anos 1990. Revista Educação e Tecnologia,
Carvalho, C. H. A. (2010). A política pública de expansão para a educação superior entre 1995-2010: uma abordagem neoinstitucionalista histórica. Revista Brasileira de Educação, 20(60), 51-76.

Cruces, A. V. V. (2005). Práticas emergentes em psicologia escolar: nova ética, novos compromissos. In A. M. Martínez (Ed.), Psicologia escolar e compromisso social (pp. 47-65). Campinas: Alínea.

Cunha, L. A. (2005). O ensino profissional na irradiação do industrialismo. Brasília: Editora UNESP.

Denzin, N. K., \& Lincoln, Y. S. (2006). O planejamento da pesquisa qualitativa: teorias e abordagens. Porto Alegre: Artmed.

Flick, U. (2009). Uma introdução à pesquisa qualitativa. Porto Alegre: Artmed.

Frigotto, G., \& Ciavatta, M. (2003). Educação básica no Brasil na década de 1990: subordinação ativa e consentida à lógica do mercado. Educação e Sociedade, 24(82), 93-130. http://dx.doi.org/10.1590/S010173302003000100005

Guzzo, R. S. L. (2001). Saúde psicológica, sucesso escolar e eficácia da escola: desafios do novo milênio para a psicologia escolar. In Z. A. P. Del Prette (Ed.), Psicologia escolar e educacional: saúde e qualidade de vida (pp. 25-42). Campinas: Alínea.

Guzzo, R. S. L. (2003). Educação para a liberdade, psicologia da libertação e psicologia escolar: uma práxis para a liberdade. In S. F. C. Almeida (Ed.), Psicologia Escolar: ética e competências na formação e atuação profissional (pp. 169-178). Campinas: Alínea.

Guzzo, R. S. L., \& Mezzalira, A. S. C. (2011). 2008: ano da educação para os psicólogos: encaminhamentos e próximos passos. In C. M. Marinho-Araujo \& R. S. L. Guzzo (Eds.), Psicologia Escolar: identificando e superando barreiras (pp. 11-31). Campinas: Alínea.

Jimerson, S. R., Alghorani, M. A., Darweish, A.-H., \& Abdelaziz, M. (2010). School psychology in Egypt: Results of the 2008 international school psychology survey. School Psychology International, 31(3), 219-228. http://dx.doi.org/10.1177/0143034310366413

Kuenzer, A. Z. (2006). A educação profissional nos anos de 2000: a dimensão subordinada das políticas de inclusão. Educação e Sociedade, 27(96), 877-910. http://dx.doi. org/10.1590/S0101-73302006000300012

Manfredi, S. M. (2002). Educação profissional no Brasil. São Paulo: Cortez.

Marinho-Araujo, C. M. (2005). Psicologia escolar e o desenvolvimento de competências. Boletim Academia Paulista de Psicologia, 25(2), 73-85.

Marinho-Araujo, C. M (2010). Psicologia escolar: pesquisa e intervenção. Em Aberto, 23(83), 15-35.

Marinho-Araujo, C. M. (2014). Intervenção institucional: ampliação crítica e política da atuação em psicologia escolar. In R. S. L. Guzzo (Ed.), Psicologia escolar: 
desafios e bastidores na educação pública (pp.153175). Campinas: Alínea.

Martín-Baró, I. (1996). O papel do psicólogo. Estudos de Psicologia (Natal), 2(1), 7-27. http://dx.doi. org/10.1590/S1413-294X1997000100002

Martínez, A. M. (2009). Psicologia escolar e educacional: compromissos com a educação brasileira. Psicologia Escolar e Educacional, 13(1), 169-177. http://dx.doi. org/10.1590/S1413-85572009000100020

Mendes, S. A., Abreu-Lima, I., Almeida, L. S., \& Simeonsson, R. J. (2014). School psychology in Portugal: Practitioners' characteristics and practices. International Journal of School and Educational Psychology, 2(2), 115-125. http://dx.doi.org/10.1080/21683603.2013.863171

Ministério da Educação, Brasil. (2008). Concepções e diretrizes dos Institutos Federais de Educação, Ciência e Tecnologia. Brasília: MEC.

Neves, M. M. B. J., \& Machado, A. C. A. (2007). Psicologia escolar e educação inclusiva: novas práticas de atendimento às queixas escolares. In A. M. Martínez (Ed.), Psicologia escolar e compromisso social: novos discursos, novas práticas (pp. 135-152). Campinas: Alínea.

Parker, I. (2014). Revolução na psicologia: da alienação à emancipação. Campinas: Alínea.

Petroni, A. P., \& Souza, V. L. T. (2014). Psicólogo escolar e equipe gestora: tensões e contradições de uma parceria. Psicologia: Ciência e Profissão, 34(2), 444-459. http://dx.doi.org/10.1590/1982-3703000372013

Prediger, J., \& Azevedo, R. (2014). Contribuições à prática do psicólogo na educação profissional. Psicologia: Ciência e Profissão, 34(4), 931-939. http://dx.doi. org/10.1590/1982-370001082012

Recebido: maio 10, 2016

Versão final: novembro 23, 2016

Aprovado: dezembro 20, 2016 